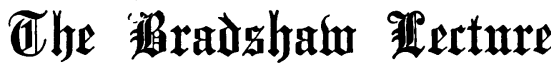
ON C A N C E R :

ITS TREATMENT BY NODERN METHODS.

Delivered before the Royal College of Surgeons of England on December 12Th, 1906.

BY EDMUND OWEN,

VICE-PRESIDENT OF THE COLLEGE AND CONSULTING SURGEON TO ST. MARY'S HOSPITAL, LONDON.

Mr. President,-In the gift let us not forget the giver nor him in whose name this Lectureship has been founded. The giver was Mrs. Bradshaw, who, in order to perpetuate the memory of her late husband, left $£ 1,000$ to this College for the endowment of an annual Lecture upon Surgery.

Never did a course of Lectures have a happier " send off" than when, in 1882, Sir James Paget delivered the first "Bradshaw." He chose as his subject "Some Rare and New Diseases," occupying himself chiefly with that chronic affection of the bones with which his name will for ever be associated, and with that morbid condition of the joints which bears the name of the illustrious Charcot. With evident satisfaction he spoke of the large amount of time and thought which he had spent in pathological museums, and, for the illustration of his discourse, brought forth out of our Hunterian Treasure-house things new and old, imparting fresh interest and importance to each by the double charm of his words and voice.

William Wood Bradshaw was a Fellow of this College and a Member of the Royal College of Physicians of London. He was for some time in practice at Reading, but he held there no public appointment, and the statement that he was mayor of the town is incorrect. A week aiter his death the local newspaper ${ }^{1}$ thus spoke of him :

He was a kind and warm-hearted friend, and during a residence of many years in this town he was ever ready to alleviate the sufferings of the poor . . . and by them his death will be especially felt.

To have earned such a character as this might well suffice to fill the highest ambition of each one of us.

The Treatment of Cancer.

Having been left unfettered as regards the choice of subject for this lecture, I have fixed upon that of cancer indeed, in various ways, time and circumstances seem almost to have suggested it. But the subject is so vast, so personally interesting, and so deeply important, that it is quite impossible for me to treat it, or any part of it, in detail. I shall, therefore, satisfy myself (though I may not succeed in imparting that feeling to others) with pointing out various directions in which the treatment of the disease has been advanced by modern methods, and by suggesting ways in which further progress may be obtainable.

I shall begin my remarks with an absolute statement (which there may be occasion to repeat later) that, in the present state of medical and surgical knowledge and experience, the only way in which the cure of a cancer can be obtained is by its prompt and thorough removal by operation; and when a surgeon has made up his mind that a growth is malignant, and that it can and ought to be removed, he should lose no time. It is more than likely that, for one reason or another, precious days or weeks have already been wasted, or worse than wasted. And, in spite of the unfortunate associations of the quotation, one may venture here to apply it:

If it were done, when 'tis done, then 'twere well It were done quickly.

The surgeon will probably be asked forthwith as to the nature of the operation advised; and this question may possibly be followed by the rejoinder that in no circum stances will consent be given to an operation by the knife. And so it comes about that a surgeon is sometimes unwillingly led to discuss the problem of treatment by $x$ rays, or by some other method based upon electricity when his opinion is that reliance ought not to be placed on anything short of a cutting operation. Thus to fall in with a patient's wish is not kindness. No surgeon in a desire to lessen mental distress, or allay the dread which a patient may have of a tumour being removed by the knife, should be led to consent to his or her dallying with any problematical scheme of treatment.

The custom has grown up of recent years for certain daily papers to instruct the public on important questions relating to disease and its treatment. Whether this is to the mental and physical advantage of the public is open to question, but there can be no doubt that people in general are taking an increasing interest in such matters. Some of the journalistic productions to which I refer are written in an authoritative, convincing, and equally irresponsible style; whilst others are, at the best, only disguised advertisements of individuals who have been permitted to bask in editorial sunshine; but the result is that the newspaper-reading public are by no means illinformed as to the lines on which surgical treatment is advancing. The subject has a weird charm for them, and details, real or imaginary, of such things as the possible therapeutic influence of the Finsen light and the $x$ rays in the treatment of malignant disease have proved specially attractive; and so it has come about that these agencies, which are still on their trial, have been popularly accredited with powers which, to say the least, cannot rightly be claimed for them, and the risk has arisen of their being exploited by the incompetent and quacked by the unscrupulous. And thus, in the desire to try the effect of specious methods, patients may be led to waste time-and time is everything in the treatment of cancer.

The public have apparently the idea that anmewhere in the invisible spectrum, beyond the $x$ rays, they are to find certain "rays of hope"; and to these they cling with increasing tenacity when they learn from the operating surgeon that, even if he be allowed to deal with a cancerous growth by a free cutling operation, he still is unable to promise a cure. And, unfortuately, no operator could ever be justified in making such a promise. Surgery must not go in advance of facts, or she will assuredly be overtaken and tripped up, as she has learnt from sad experience. At present it is beyond her power to promise to cure cancer, whether by a cutting operation, by $x$ rays, by Finsen's light, or by any drug or nostrum injected into the blood, taken internally, or applied locally. Treatment is, unfortunately, not the same thing as cure, and the most effectual treatment for cancer-no matter how small it may be-is still removal by the knife. No measure is so trustworthy as this, and the great advantage which it has over every other is that it enables the surgeon to take away also the neighbouring lymphatics, and the outlying lymphatic glands. It is by the freedom and thoroughness of recent improvements in operating that surgery has made such great advances in the treatment of the disease. That she has advanced, and is still advancing, is beyond dispute. But all that the surgeon is at present justified in promising a patient is that he will do his best. And with this in view he makes a wide sweep of the growth with his knife, getting so far beyond it, indeed, that he may well hope and believe that, together with the tumour, he has taken away every outlying cancer germ. But, notwithstanding his wide sweep, he cannot be sure that none of these germs had already passed beyond its range. And a cancer germ adrift in the lymphatic stream is like a message thrown out to sea in a bottle-it may be found years afterwards, who can say when or where?

\section{Cancer of the Breast.}

It would be impossible for me to allude to the advances which surgery has made in recent years in the treatment of cancer of the breast, without speaking of the work done in this direction by the late Sir William Mitchell Banks. I regret to say that his teaching has not received in this country that recognition which was its just due. Too much is it the fashion here, when surgeons are writing upon any professional subject, to quote German, American, French, or unpronounceable Russian authorities, and to leave in the cold shade of neglect all that has been done by workers near at hand.

Banks was one of the very first surgeons in the whole world to show that if we were to obtain better results for our operations on cancerous breasts, we must be more thorough in our dealings with them.

His earliest essay ${ }^{2}$ on the subject appeared in 1877, just on thirty years ago, and in it he insisted on a greater thoroughness. 
His second paper was read at the Worcester meeting of the British Medical Association in 1882. Its title was On free removal of mammary cancer, with extirpation of the axillary glands as a necessary accompaniment. ${ }^{3} \mathrm{He}$ was then preaching from the text of the need of clearing out the armpit, and he said, "until we have these glands in our hand, and have split them open with a knife, we cannot tell whether they are infected or not. The usual fumbling in the axilla, which is practised by surgeons" (this was written twenty-four years ago) "tells nothing," and he urged that in every case where the breast is removed the axilla should be cleared out as a necessary accompaniment.

His third paper ${ }^{4}$ was read before a meeting of the Harveian Society in 1887. In it he insisted that by clearing out the armpit, as part of the operation for the remova of a cancerous breast, "the duration of life was prolonged, and the recurrence of cancer less often took place."

It is well worth the while of any surgeon who is interested in the work of Banks having bare justice done to it to turn up the report of the discussion on that Harveian paper, and to see how poor a measure of support it received. The address was in Banks's happiest, most breezy style and those who heard it, and those who read it subsequently, should have no need to steam across the Atlantic Ocean or the North Sea to find the surgeon who has been the chief pioneer in the more thorough treatment of cancer of the breast.

Having written these few words in devoted memory of Banks, I see him once more in my mind's eye-a welcome speaker in the Council chamber of this College, or at some professional or social gathering. No need when he was speaking, Ulysses-like, to stuff one's ears; the magic of his words was all for good. There was a something about them which showed that they came from his heart as well as from his head; and this not only gave them the stamp of downright honesty, but also made them full of life. No one, I admit, could claim that they never caused a passing wound. How can a man who speaks from his heart help that at times? As he feels so he speaks; and though this may not make for popularity it does for honesty. And B.ınks was honest as the day. He would doubtless have agreed with the great Lord Mansfield-that not that popularity is to be desired which a man seeks for himself, but rather that which follows him. In spite of his fearless words, popularity followed Banks; and it is not too much to say that those who knew him loved him.

In connexion with the subject of the modern treatment of mammary cancer, I would like to insist that, when a surgeon is setting out to operate, he must not have a thought as to how he is ever to get the edges of the wide wound together subsequently. The one important thing for him to do is to cut clear of all tissue that may possibly be infected. Nature can be trusted to heal the gap that he needs must leave, and he may draw heavily upon her.

In the early stage of his operation, when he is working deeply at the inner end of the wound, he should cut down until he has laid bare some of the fibres of origin of the pectoralis major, then he should get his finger-nail under the pectoral fascia and peel it with the breast, and superjacent skin, in one mass, towards the axilla. In this way, with great rapidity, the muscle can be left as bare as after a prolonged dissection. In most operations the fat and the glands in the armpit can be easily cleared out by using the finger and the blunt dissector. And I think that the ideal way of operating is that which enables the surgeon to remove breast, skin, pectoral fascia, lymphatics running to axilla, and the axillary fat and glands all in one bulky mass-and to do it quickly.

I cannot believe that it is necessary to remove the thoracic part of the pectoralis major as a routine practice (as some advise), even when the breast shows no attachment to it. One surgeon of experience tells me that he now always takes away the muscle lest its subsequent contraction should cause the arm to be bound to the side. This practice does not appear to me to be advisable. Of course, if there were invasion of the muscle, it should be sacrificed upon the altar of thoroughness. But it is not as if the lymphatics from the breast passed through it on their way to the axillary, the cervical, or the mediastinal glands.

Cancer of the Lip.

To excise an epithelioma of the lip without opening up the submaxillary region, and clearing away the lymphatic glands is to invite disappointment, for the glands contain epithelial growth almost as surely as did the labial sore, and if they are left it is but a question of time when they will involve the neck in malignant ulceration. They should be dissected away whether they are apparently involved or not.

A few years ago the operation for epithelioma of the lip was deemed of slight importance-an operation that might almost be handed over to a dresser. A thick wedgeshaped piece of the lip was removed, and the edges of the wound were neatly adjusted by sutures. And because after this the lip scarce showed a mark, everybody was satisfied. But when, later on, the glands beneath the jaw began to enlarge, to break down and to ulcerate, satisfaction gave way to disappointment, and disappointment to remorse. That simple operation of the removal of a wedge from the lip is now, happily, a thing of the past. The modern method demands the free use of the knife, so that not only the tissue may be incised wide of the growth, but also that the whole submaxillary region may be opened up and cleaned out bare, so as to get rid of all the lymph channels. The existence of these lymph vessels, which linked up the cancer and the lymphatic glande, has too often been lost sight of, not only in the case of cancer of the lip, but in cancer of other regions also. The surgeon examining for the presence of enlarged lymphatic glands, and, finding none, was apt to say to himself, "It is in good time; the glands are not yet affected." And all the while epithelial seeds were steadily travelling along the delicate vessels, the fact being unrecognizable by either sight or touch. To cut out the cancer and excise the gland, and yet to leave the intermediate, full-charged, lymphatic vessels, is but a slight improvement upon the old operation of removing the labial wedge. All should be taken away.

To see the thoroughness of the modern operation for cancer of the lip, reference may be made to the Practitioner for last July, in which is an able and a well-illustrated article by Mr. Lenthal Cheatle.

Briefly, if the surgeon is going to excise a wedge-shaped mass, the apex of the wedge is to be represented by the tumour, and the sides are to spread away to such a degree that when their distant ends are joined by a cross-cut, all the loaded lymphatics and the infected glands may be taken away with the cancer. And in planning the incisions the surgeon is to be guided by the course of the lymphatics rather than by the desire of leaving the patient a good-looking lip.

In this modern operation for cancer of the lip, some surgeons, ${ }^{5}$ in their desire for greater thoroughness, tie the facial vessels, and then remove the submaxillary salivary glands, and all the lymphatic elements from one angle of the jaw to the other, as well as the glands over the carotid bifurcation. If the epithelioma had a lateral situation they might be content to clear only the corresponding submaxillary and carotid regions; but their operation must be thorough.

And even if the growth seems to be so adherent, or so widely spread that operation can offer the surgeon but a poor hope of his being able to get it all away, still I would be in favour of his making the trial. It not seldom happens that, when a surgeon has gone some distance with an operation, difficulties which had previously seemed wellnigh insurmountable are completely vanquished, and the business is brought to a happy ending. It is, moreover, a great satisfaction to the patient as he looks back-even if the operation were disappointing in its results-to feel that he unflinchingly took the chance, even though the odds were heavily against him.

Cancer of the Tungue.

Cancer of the tongue is of great local malignancy, in that it quickly infects the lymphatics and the lymphatic glands, but it differs from other cancers in that it is inclined to leave distant organs alone. Therefore, if the local affection can be removed. root and branch, the outlook should be promising. But there is an unhappy feature in the lymphatics of the tongue which is apt to spoil the best-laid surgical plans; it is that they do not. observe that anatomical precision which nerves, arteries, and even veins are accustomed to follow, but, passing irregularly across the median plane, may bring infection to the glands on both sides of the neck, whilst the lingual ulcer, perhaps still small, remains one-sided. The result of this, as it affects modern methods, is that the 
surgeon is less inclined than he was formerly to remove half a tongue for cancer; and that in those cases in which he excises the whole tongue, he may think it desirable to clear out all the lymphatics and lymphatic glands on both sides of the neck. This, of cuurse, adds to the gravity of the modern operation, but it renders it far more complete and promising.

Without fear of contradiction, I will say that no surgeon has done more towards making the operation for cancer of the tongue thorough and efficient than Mr. Butlin. Chiefly by his teaching and example, cases are now brought within the scope of practical surgery which, a few years ago, would have been hopelessly shut out, whilst the chance of obtaining a permanently good result has been greatly increased. Mr. Butlin's operation for cancer of the tongue ${ }^{6}$ is planned upon the same lines as those of the modern operation for cancer of the breast. That is to say, not only is the tongue removed, but the lymphatic glands, and the Jymphatic vessels which run from the tongue to the glands, are also cleared away. The submental, the submaxillary, and the upper and lowe carotid lymphatics are all to be dissected out, together with the submaxillary salivary gland, and the anterio triangle of the neck is to be left just as naked as the armpit is left after the complete operation for cancer of the breast.

Needless to say, it is a trying and anxious operation but to the surge'sn who, by a longer apprenticeship, is used to operating upon tuberculous cervical glands, it offers nothing of alarm or difficulty.

In some cases it may be best to perform this operation at the time that the tongue is removed by the sub maxillary (Kocher's) route, but perhaps the supplemental, or rather the complemental, operation can be more conveniently and safely carried out ten days or a fortnight after the excision of the tongue. The operator need not insist upon the clearing out of the carotid regions on both sides of the neck in those cases in which the cancer is absolutely one-sided, and there is no evidence of bilateral glandular infection. But, in view of the uncertainty of the course which the lymphatics may take, he must be always on the look-out for the hint that he must carry out the two fold clearance.

Modern methods of investigation and procedure are confining within limits of ever-increasing narrowness those chronic inflammatory conditions of the tongue which made up the clinical picture of the so called precancerous stage of lingual cancer. Far less time is now spent in watching their behaviour under expectant treatment, for experience has abundantly shown that their course was almost always in that direction in which the possibility of further doubt could, unhappily, no longer be indulged in.

Our forefathers would not fail to be astonished at the thoroughness with which the modern operative methods deal with cancer. To them the presence of enlarged glands was almost looked upon as a bar to direct interference, and they might likely claim that in their days patients could not have successfully undergone such serious operations. They might even go so far as to suggest that this toleration had been begotten only by the training which all and sundry patients had undergone since their time, in order to fulfil the demands now made by the surgical profession. Our reply would be, however, that probably men and women have no greater power of resistance to-day than they had 50 or 100 years ago, but that the possibilities and triumphs of modern surgery must be ascribed, to put it figuratively, to Lister having shown us the virtue which lies in the proper use of soap and water, and a nail-brush.

The Method by Local Starvation.

If a tissue does not receive its needful supplies of blood it becomes degenerate. This is seen in the wasting of the testis which follows obliteration of the spermatic artery; in the flabbiness of the muscular tissue of the heart when the coronary vessels are ossified. and in the softening which takes place in the brain when, as the result of syphilitic deposit, or of chronic arteritis, a clot has formed in the middle cerebral artery.

Dr. Dawbarn, of New York, has recently founded a method of treatment of cancer upon this well-known pathological phenomenon. He describes it as the "starvation operation for malignancy in the external carotid area," and he gave an account of it in the Journal of the American Medical Association for September, 1904 . In thus introducing it, he modestly asked that the method might be allowed the justice of a thorough study and trial, by which alone its corroboration or overthrow could be effected.

He seemed to be disappointed that so few surgeons had up to that time made trial of the method. But inasmuch as it entails a great demand upon the resources of the patient as well as upon the determination and enterprize of the surgeon who proceeds to carry it out. there is small wonder if, on looking back, he sees but few of his confrères following in his steps. Still, the szheme rests upon a solid foundation, and is worthy of respectful consideration amongst the modern methods of treating malignant disease. Dr. Dawbarn admits that it is likely to secure better results in sarcoma than in cancer inasmuch as that disease spreads chiefly by the blood vessels, but he claims for it a field of great usefulness also in some of the very worst cases of cancer. Taking the case of advanced inoperable cancer involving the lower jaw, he excises the whole of the external carotid artery on each side, the operations being done "for safety" at different dates. He ties the inferior dental artery and its mylo-hyoid branch at the entrance to the inferior dental canal, so that there may be no chance of blood finding its way into the jaw through the generous anastomoses of the internal maxillary artery with the internal carotid. But when he comes to consider the application of "the starvation method" to malignant growths involving the orbit, he throws up his hands in despair in view of the impracticability of clearing away the entire external and internal carotid arteries on both sides. His plan for cutting off all chance of blood finding access to the malignant mass by means of anastomatic loops certainly does not err upon the side of inefficiency. Having begun to dissect away the external carotid, he follows the vessel up into the parotid gland, and injects into its distal end a fluid mixture of hard white wax and vaseline. This he calls supplemental treatment, its object being to prevent all chance of a reversed arterial flow by plugging the superficial temporal and internal maxillary. But he offers the caution that sometimes the vessel which is giving off the external carotid branches is actually the internal carotid and that if in these circumstances the operator should inject the upper end of the artery (under the impression that he is about to block the internal maxillary and superficial temporal), he will cause a fatal plugging of the circle of Willis. In his operation for resecting the external carotid, he removes also the veins which present themselves to his view, thinking that their absence will be a further check upon the establishment of collateral circulation. He makes it to be clearly understood that both external carotids are to be similarly dealt with, allowing an interval of two or three weeks between the operations, and he urges that the vessel which is apparently the less concerned with the growth be first dealt with. He says that if the artery which seems the more concerned with bringing supplies to the malignant mass is first operated upon, the improvement is so great that the patient believes that enough has been done to effect his cure, and, therefore, declines further treatment. That subsequently the opposite artery does double work, and that the end is disappointment. That to excise one artery and leave the other "is simply a waste of time," and he is of opinion that this is equally true with regard to ligation of both arteries "without vascular excision." 'This refers, of course," he continues, "to control of malignancy." But he strongly advocates ligation of both external carotids before carrying out extensive operations for the removal of malignant growths of the face and mouth. And, looking forward, he thinks that he sees the time when this step will "come into regular emplopment before such otherwise bloody work."

When a surgeon is examining a malignant mass in the mouth with a view to its removal, his chief thought is in connexion with the bleeding which must inevitably attend the operation. And when, as must often happen in these cases, he decides to expose the side of the neck for the preliminary cleaning away of enlarged lymphatic glands, it is but a short step to tie off the external carotid artery and thus simplify the future operation. So beneficial has the starvation method proved in certain cases of 
inoperable cancer, that Dawbarn hopes to gain on an average a year by its adoption. He has seen masses shrink and become so much less painful after it has been performed that the patient has been able greatly to diminish the amount of morphine which he had previously been compelled to take.

Dr. da Costa tells of a man with an extensive cancer of the face which two distinguished Philadelphian surgeons had declined to attempt to remove. In this state of hopelessness da Costa performed carotid excision on both sides. At once the growth began to shrink, and a few weeks later he was enabled to excise it. This report shows that by local starvation an apparently hopeless cancer may be brought within the range of practical surgery. The operation is, of course, a very serious one, but in such advanced cases no operation of less severity could possibly be of avail :

Diseases desperate grown
By desperate appliance are relieved Or not at all.

Operations and Statistics.

In reviewing these various methods it would ill become the most conservative of us to condemn; or to stand upright and stiff in the temple of Esculapius, and, with self-satisfied look, express smug thanks that he is not under the influence of such restless surgical activity. In the direct treatment of cases which are otherwise hopeless, we must allow freedom of judgement and action to the honest and enterprising surgeon, and if personally unwilling to lead a forlorn hope, we must not try to hinder others whose judgement may, after all, be just as good as our own. In the world of therapeutics there are still dark tracts and continents which can be discovered only by men of imagination and energy ; and possibly the Columbus or the Raleigh is to-day with us who, later on, will bring back the glad tidings that he has found out the nature of cancer, and can tell us of its cure. And when this happens, there will be no need for him to "cry aloud" in the pages of the British Medical Journal in order to convince, or to "strive" upon its cover. Nor will the discovery have to be made manifest by columns of figures and percentage calculations of cures, which, like pancakes on Shrove Tuesday, have to be served up quickly, lest delay should spoil them. But it will be as the lightning under heaven.

To deal with percentages as applied to human beings may be correct enough when figures are worked out in large numbers by an unemotional, disinterested actuary in tho office of a Life-insurance company ; but I do not look upon such calculations as of real, practical value, when they are compiled by a surgeon, in his evening leisure, to set forth the result of his own treatment of certain sick people. Two patients with a disease called by the same name are not of the same clinical value, nor are 20 , nor 200 , and the sooner Surgery discards the actuarial method in setting forth progress in connexion,with the treatment of cancer the better.

Again, in an almost pardonable wish to show the results of his operative work in an attractive form, the surgeon is sometimes tem.pted to set up for himself a "time limit," and then to say, "If after operation for cancer there is no sign of return in any part of the body within this period, I shall count the case as cured." After all, this time limit of his is but arbitrary. One surgeon may fix for himself a ten-years' limit; whilst another, who is, perhaps, more sanguine, makes his a three-years' limit. And if three years, "why not three months? But can a surgeon who looks at facts, rather than at figures and fancies, rightly claim the three-year group of operation-cases, or even.the ten-year group, as cures? I think not. It may be more than ten years before that little mass of drifting cancer cells is, by chance, found cast up in some outlying area of tissue.

Treatment By InJection.

Two years or so ago "all Paris," and a great many other people, were set talking about a method of treatment of cancer which had sprung from the brain of Dr. Doyen, a surgeon of acknowledged manual dexterity and enterprise. Much was expected from it, especially as he said that his inspiration had been drawn from the work which Pasteur had done in the treatment of rabies and Koch in the treatment of tuberculosis.

In the Introdustion to his large book $^{7}$ he explains how his first observations upon what he took to be the pathogenic microbe of malignant tumours, were sent in a sealed envelope to the Académie des Sciences in 1886, and that fifteen years later he named this microbe Micrococcus néformans. That after waiting another three years he had the sealed envelope opened and its mysterious contents made known, for he was of opinion that his further experiences had fully confirmed his early hopes. And in these days of notoriety-seeking and advertisement, one can but admire the restraint which, up to that time, the French surgeon had imposed upon himself in keeping his experiences in the treatment of cancer hidden from public view. He said that he had found certain microbes in various malignant growths, and in the cancer-juice of infected glands, and he asked if these micrococci were without importance, or if they were of the nature of a special ferment of pathogenic property and capable of reproducing themselves. This, briefly, is a review of his position : A microbe infects the edges of rapidlygrowing malignant tumours, which he calls micrococcus neoformans; this is the cause of the growth just as the bacilli are of tubercle, or as the ray-fungus is of actinomycosis. That the neoformans may be cultivated, and that cultivations injected into certain of the lower animals may produce a growth very like cancer. That injections of the culture into persons affected with cancer sets up a reaction comparable with that following the injection of Behring's serum in the subject of tuberculosis, and, lastly, that injection of the serum in the subjects of malignant disease retards the growth of the tumour or even causes it to disappear. If this were actually so, he would probably have been justified in heading one of the paragraphs of his book in large type, Vaccination anticancéreuse préventive et curative.

The reading of the book, however, does not bring conviction. It will be noticed, for instance, that in nearly all the cases which he claims as evidence of the value of his injection treatment the patients had, in addition, been submitted to operation by the knife. He himself is apparently struck by this fact, for he would have his reader specially remark that in the successful cases numbered 62,78 and 79 there had been no operation on the cancer deposit itself. Case 62 is one of "pyloric cancer" which he had treated by gastro-enterostomy, and No. 78 relates to somp enlarged glands under the jaw arising after the removal of an epithelioma of the cheek by some other surgeon. Doyen truly remarks that a certain diagnosis of cancer could be made only by examination of the glands after removal, and this was not done, for the enlargement disappeared. The 79th case is that of a woman whose vaginal wound did not heal after hysterectomy, though it cicatrized after the " antineoplastic" injection had been used. There is no proof that the local trouble in these persons was cancerous. And as regards the stomach-case, I would remark that it has probably fallen to the lot of most surgeons with experience in the operation of gastro-enterostomy for pyloric obstruction, to meet with a pleasant surprise of th is nature. The abdomen having been opened, and the small end of the stomach having been reached, a mass of wooden hardness is found blocking the outflow; and this mass may also be so firmly fixed that the surgeon has finished his operation in the belief that it could be nothing but cancer. However, after the operation, the patient has steadily become strong and robust once more, and the question of the growth having been cancerous has happily and finally to be abandoned. This, I say, is no uncommon experience, and I venture to think that the case which the French surgeon professed to have cured by the serum injection was of a similar nature.

In March last a paper was read before the Roya Medical and Chirurgical Society of London ${ }^{8}$ by Drs. Alexander Paine and David Morgan on a series of cases treated after Doyen's method. Doyen had himself seen most of these patients, and had regarded them as suitable for the treatment. No other surgical measure was used with them. In some of the cases the injection was followed by severe pain; and in some it caused alarming symptoms, with sudden, widespread vasomotor disturbance and collapse. All of them went steadily downhill; "in none was there any improvement," and "it was decided to suspend the treatment" Further, Drs. Paine and Morgan reported that they had sought, found, and cultivated the micrococcus n $n$ oformans in many cases, and having injected rats and mice with serum duly prepared 
from it, could obtain no local results other than those of an inflammatory nature. In no single instance did they succeed in producing any approach to a malignant tumour, nor, so far as their knowledge went, had Dr. Doyen ever succeeded in producing it.

The Imperial Cancer Research Fund.

I feel that I should be neglecting this opportunity if I did not specially refer to the work and claims of the Imperial Cancer Research Fund, which was established four or five years ago under the common roof of the Royal Colleges of Physicians and Surgeons. As a member of the Executive Committee $I$ am in a position to know, and able to give assurance to those interested in the welfare of the Fund, that the Director, Dr. Bashford, and his staff are steadily, patiently, and hopefully plodding away at the mysterious problems of the cause and cure of cancer. But at the same time I am sorry to say that they are running the risk of being hampered in their researches by the somewhat limited space in which they have to carry on the work, and by the inadequate amount of skilled assistance which the Executive Committee are able to afford them. As regards the cramped accommodation, we are assured that the Fund is at present, from shortness of income, unable to make better arrangements. And as regards the supply of further competent helpers, our President, Mr. Henry Morris, who is regretfully compelled to hold the purse-strings somewhat tightly drawn, is inspired by a dread (which bears tribute to his capacity as Treasurer), of the Fund living beyond its means.

At the time that Italian Art was at its highest pitch, rich and large-minded men were proud to come forward and stand as "Patrons of Art"-a position which was not without occasional advantage to themselves, as they were thus enabled to see and acquire treasures which might otherwise have been missed by them. At the present time in England Science is in want of such men. Fortunately, we have already some with us-fortunately, indeed, for without their help this Cancer Research Fund could scarce have been established. But more are needed. And I am sure that I shall have the approval of our President when I say that each one of us should take every opportunity of making known the existence, the objects, and the needs of the Fund to any one who may be at all likely to come to our assistance.

But in becoming a "Patron of Science," so far as this great Cancer-problem is concerned, the individual can expect no prompt or visible return for his bounty; he will have to be content with the knowledge that his gift will be faithfully and economically administered, and with the reasonable hope that it may help to bring relief to some unknown persons who, perhaps in the very prime of life and usefulness, are overtaken by a peculiarly distressing and intractable disease. We are given to understand that when, as now, times are financially bad, men are apt to be sorely troubled as to the security in which they may invest their spare money with the greatest advantage and least anxiety. Here, then, is a golden chance for them! And, having availed themselves of it, there will be no need for them to turn with eager glance to a certain column of the Times, and, with the risk of losing appetite for breakfast, find how the stock is quoted. For the present, only once a year will this great imperial trust be officially mentioned, namely, after the annual meeting under the Chairmanship of His Royal Highness the Prince of Wales, the President of the Fund. But I must not hide the fact that it is a matter of growing and sincere regret that the number and the amount of yearly subscriptions to this Fund have lately somewhat fallen off. It is as if certain of its early friends had grown disheartened because, after the ploughing, the sowing and the reaping of the quick-elapsing time, a full harvest had not already been gathered.

In these circumstances, it is a great satisfaction to those who are practically and confidently interested in the success of the Fund to know that, by the liberality of our Patrons of Science, the Fund has now an endowment of $£ 116,000$ (inclusive of the splendid Golden Wedding gift of Mr. and Mrs. Bischoffsheim). But in order to ensure its continuous, even, and unpinched working, its endowment ought still further to be increased. To put it bluntly, the Fund wants about $£ 20,000$ more. It would, I should think, be impossible to find upon the front page of the "prospectus" of any other undertaking the names of men better known or more highly respected in the world of philanthropy, of finance, and of science. And the friends of this Fund need no assurance that these names stand at the head of our reports not for the purpose of decoy, but as proof of the righteousness of the scheme and of the practicability of its success.

But should this looked-for success happily be reached in the near future, so that further need of Research in the matter of cancer might be considered at an end, a Special General Meeting of the Supporters of the Fund would be called, so that a decision might be arrived at as to the way in which the invested capital or the income should thenceforward be dealt with. But this is surely yoing too fast: As La Fontaine's bear whispered into the ear of the eager hunter, one should not arrange for the sale of the bear's skin whilst the animal is still alive.

Comparative Study of Cancer.

One of the first matters to which the Director of the Research Laboratory turned his attention, was to ascertain precisely how far down the Animal Kingdom cancer could actually be traced. And in the course of this inquiry he discovered the interesting fact that amongst the lower vertebrates, as with the human subject, there is a close association between the incidence of cancer and advancing age. Thus, out of 63,000 head of cattle slaughtered in Glasgow in the year 1902, cancer was detected in 27 cases, but all in old cows sent over from Ireland. As a rule, a cow is killed before it reaches the cancer-age, and this is probably, the reason of the comparative smallness of the number of malignant tumours met with in the slaughterhouse; but where cows are kept on year after year for purposes of haulage, or for other reasons, a liability to cancer increasingly shows itself. In the examination of upwards of 100,000 mice, 42 cases were found, but a large number of them were young mice. The extreme age of mouse is three years, and cancer is most likely to hit it in the second or third year. And in the case of horses, dogs, cats and fish this same association of age and incidence is regularly noticed.

In these days, when well-meaning but over-zealous persons are for ever telling us that the chief part of our illnesses are brought on by our own misdeeds, and especially by even a moderate indulgence in what they are pleased to call "alcoholic beverages," it is something of a comfort to find that the trout and the carp, undoubted water drinkers, are, with the rest of us, liable to cancer. And if so be that the record of this consoling fact be read by any of those either inside or outside our profession who take their recreation with rod or gun, I would beg that if at any time they meet with an animal marked by some strange growth or diseased patch, whether the animal be clothed in feather, fur, or scale, they send it forthwith to the Director of the Imperial Cancer Research Fund on the Victoria Embankment, where, I can promise, it will be cordially welcomed and carefully examined. Such specimens may prove of the utmost value to those engaged upon the great cancer-problem, and by giving themselves this little trouble the senders will be materially helping our patient workers, as well as showing sympathy with their work.

And here I would express the grateful acknowledgement of the Executive Committee of the Fund for the favourable response which their Deputation received a few months ago from the Postmaster-General to their request that specimens, if securely packed, might still be sent through the post to the Director of the Laboratories. Taking advantage of these postal facilities, the Headkeeper of the Duke of Rutland recently sent to the Laboratories an old cock grouse who was found to have a cancer of the bowel ; and Mr. Goodall and Mr. Cousens, Fellows of the Royal College of Veterinary Surgeons, have forwarded, respectively, a blackbird with cancer of the liver, and a canary with cancer of the ovary. All these specimens were of great interest, and more of them are desired.

It is strange that at present the wouse is wellnigh the only animal in which cancer can be obtained by grafting; that cancer-grafts from a mouse will not grow continuously in other animals, even in one so closely allied as the rat; and that the graft is so particular that it will take root only in mice of the same species. A graft from a tame mouse most likely perishes in the tissues of the 
common grey one, and a graft from a cancer-infected English mouse will seldom live in a German mouse.

It is likely that the question of experimentation upon mice in the laboratories of the Imperial Research Fund will receive mention at meetings of the Vivisection Commission, and that some misinformed and, therefore, apprehensive witness, or some Little Englander of the Science-world, may be asking himself what profit can be forthcoming from such experimentation, claiming that mice are of more value than many human beings who are or may be the subjects of cancer, and demanding that further experimentation-the only means by which a cure for cancer is likely to be discovered-shall forthwith cease. As to the precise value of the work it is set too early to speak; but seeing into whose care the direction of the laboratories has been placed, the public may trustingly await results, and in full assurance that no cruelty will be allowed to dishonour the research.

The inoculation of the mice with cancer is done by the mere prick of the skin with a slender, hollow needle; it is no more a "vivisection" in the ordinary acceptance of the word than the giving of a hypodermic injection to a patient is a surgical operation. And, as regards the mouse who has thus been rendered cancerous, he is, to all appearances, except in extreme and unusual circumstances, as comfortable as his companions are. But even were facts the reverse of what $I$ have stated, and of what I know them to be, I should still claim that if there is a chance of Research bringing forth something for the relief of men and women who are suffering from cancer, it is more than justified-it is sanctified. . And this, I think, would be the opinion of the ordinary run of English people. And should the attempt be made blindly to cause this great and promising work to cease -a work to the perfect success of which even the most uncompromising opponent to experimentation on living animals can scarcely be indifferent-the stones would immediately cry out! Experimentation with, and the careful microscopical examination of the tumours which grow from transplantations in mice, show that spontaneous and propagated cancer are, so far as can be made out, identical. This is of importance to Laboratory workers, as it enables them to secure an unlimited supply of living and dead cancer-material; to watch the behaviour of the disease in the earliest days of its growth, and to study the effects of treatment in the most impressionable age of the morbid tissue.

And here I may say that amongst the various attempts which have been made to modify the growth of wellestablished inoculation-cancers, the results obtained by exposure to radium have given very little encouragement. And so it has been with the experimental study of the reputed empirical remedies which, from time to time, have been forwarded to the Laboratories to be tested-one and all, they have proved complete failures.

\section{The "Cure" of Cancer.}

At the annual meeting of the Fund held on July 25th last, it was officially announced that due attention had been given to the examination of various so-called "cancer-cures," but that investigation had failed to show that any value could he attached to them. This is, at any rate, an assurance to the public that the Committee are taking interest in the practical, as well as in the scientific side of the question, and I am in a position to state that they are at all times ready to make impartial investigation of any such claims.

The Committee then go on to say that they " cannot but regret the publicity afforded from time to time in newspapers and periodicals, to very misleading notices in favour of the numerous so-called cures." Cure is the one word which appeals to the public, and naturally so. As one reads the quack advertisements continually appearing in the public press, one sees how every trap is baited with the promise of cure. In the dealings of the cunning quack with the anxious patient there is no suggestion of uncertainty; a cure is promised as soon as the money is paid. Whether the disease is cancer, tubercle, rupture, gout, or alcoholism, the quack is ready not with mere treatment, but with the welcome promise of certain cure. And this is what the public desire. They like being deceived; and the lay press (and especially the so-called religious newspapers) does its best to help. But in these days when public journalism has obtained for itself so high an estate, it is pitiful to see the class of people whom certain newspaper proprietors welcome to their columns as "paying guests." The newspaper man may claim that of the fraud he knows nothing; that he is of so innocent and trusting a nature that he takes as gold everything that glitters; and that with the disappointment, the remorse, or the financial ruin which may result from his spreading abroad shamefully misleading advertisements he has really nothing to do. Quackery is, of course, much older than the public press, but at the present time it is by means of the public press that the quack is enabled to gather in the greatest part of the rich harvest which he reaps from the suffering and the ignorant.

Is it too much to hope that as time goes on it will be made illegal for any one to act as a medical practitioner unless by study, examination, and registration he has acquired the right and the privilege to do so? In some respects England is far too free a country, and though an impostor may not act as a clergyman, a policeman, or a lawyer, he may at any time set up as a cancer-curer, in which position he is apt to do grievous harm to the individual, not only by robbing him of his money, but by delaying his coming under that method of treatment which, so far as is known at present, is the only one which can offer him any real prospect of relief.

I regret that it is out of my power to call attention to any modern method of treatment of cancer which can honestly and confidently promise a cure. As yet, Surgery knows of none. Nevertheless, the surgeon may be able by operation to do a great deal for the individual, may be able, indeed, to set him quite free from his disease. But the word cure, if used at all, must at present be mentioned only in a whisper, as it were. Later on, perhaps, it may be proclaimed upon the house-tops. It is, of course, disheartening to be compelled to confess that no certain cure for cancer has as yet been found, and that, so far as is known, searchers are not yet upon the obvious track of one. But such is the fact; and it is only right that the Public, who, equally with our Profession, are interested in the long-wished-for discovery being made, should know just how matters stand. The Public may be assured of this, that if a cure were known, those who are strenuously working at the subject would be in immediate possession of it. And it may be that if the exact position of affairs could be placed before the Public, it might have the effect of inducing more people to give financial support to the great National Fund which has recently been established in England for the prosecution of Cancer-research, as well as of preventing some of those who believe themselves to be the subjects of that disease, from falling blindfold into the hands of the so-called "Cancer-curers."

One fact of importance obtained in our Research Laboratories, in the course of inoculation experiments upon mice, is that, every now and then, a mouse which has been infected with cancer gradually triumphs over the disease, and at last gets entirely free from it. The same thing sometimes occurs in the human subject-an undoubtedly malignant deposit steadily growing smaller, and eventually fading away. Unfortunately, this takes place so rarely in the human subject that it is impracticable to hope for it. But it may happen; and in cases in which the disease is regarded as inoperable, the surgeon does not lose sight of this possibility. And when he hears non-medical friends or neighbours discussing some extraordinary case in which, under gentle treatment by coloured liquids, by violet-leaves, or by goodness knows what, a tumour which had been called a cancer has been cured, he is likely to say to himself that if it were a cancer (which, perhaps, he may make so bold as to doubt), this was probably one of those rare instances of spontaneous cure. The question arises as to what there was in those mice, or in that happy individual, which enabled the natural forces to vanquish the disease. And as soon as we are able to imitate that process in the Labnratories, the cure of cancer will be within our reach. Is it due to some extraordinary property in the colourless blood-corpuscles which has, scmehow or other, been awakened into activity, so that the cancer-cells-which, in the absence of proof of the existence of specific cancer-germs must still be deemed the essence of the disease-are routed and destroyed? In this direction experimenters are already at work, some with drugs administered by the mouth ; others with injections of sterile cultures of potent germs; others with 
animal or vegetable juices; with chemical solutions, or with emanations from radium or from the electric arc.

In the course of their experimentation upon mice, Drs. Bashford and Murray made the discovery that by injecting a few drops of blood from a normal mouse into the circulation of a healthy mouse on which they are about to graft a cancer, they can effectually prevent that graft taking root, though blood of a rat or of a guinea-pig similarly injected has no such protecting influence on the mouse. If these results be confirmed by other workers, the next thing will be to find out why this happens. And if it be conceded that the mere injection of a few drops of healthy blood can prevent the mouse becoming a prey to cancerous infection, the thought comes home to us that, after all, it may be only some small thing which is needed to check the progress of a cancer by which a human being is infected -it needs but an infinitesimal amount of vaccine lymph to render a whole country proof against the ravages of small-pox. The time is surely ripe for the advent of a Jenner in the world of cancer !

\section{Prospect and Greeting.}

In virtue of my position as Bradshaw Lecturer, which has thus enabled me to take in view the chief modern methods of the treatment of cancer, and to cast wistfu glances upon the prospect of the perfect understanding of and the eventual triumph over, that disease, I seem for the moment to be standing, as it were, upon the top of Pisgah and looking " to that good land that is beyond, that goodly mountain "which Surgery promises herself shall, in the fullness of time, be made her own. And the thought naturally arises as to the exact way by which this happy descent will be effected. In the midst of much that is uncertain, I feel sure that the final victory over cancer will not be solely by the knife. Excision of the cancerous growth has rightly been practised as long as Surgery has been an Art, and of late with increasing thoroughness and success; and though this has enabled us to accomplish great results, even to the effecting of absolute cures in undoubted cases of cancer, yet, even in its freest exercise, it leaves much to be desired. But whatever the great curative method may eventually prove to be, the knife will, in all probability, still be needed for the removal of the primary lesion.

And having thus ventured to compare my position with that of Moses as he looked towards the Promised Land, I think that I cannot do better than bring my remarks to a close by using the last verse of the Chapter from which I have already made quotation; it contains the cheering, hopeful exhortation which was to be given to Joshua And I will make so bold as to pass it on, with a mere change of pronouns, as a respectful greeting to the Imperial Cancer Research Fund, which, guided by our two Royal Colleges, has the high distinction and advantage of carrying on its work under the immediate patronage, and with the keen personal interest of His Royal Highness the Prince of Wales. The message runs thus: "Charge them, and encourage them, and strengthen them; for they shall go over before this people, and shall cause them to inherit the land which ye shall see."

1 The Reading Mercury, August 25th, 1866. 2 Liverpool and Manchester Medical and Surgical Reports. 3 BRITISH MEDICAL JouRNAL 1882, vol. ii, p. 1138. 4 Ibid., 1887, vol. i, p. 572. 5 See paper by J. Hutchinson, jun., BRITISA MEDICAL JouRNAL, May 26th, 1906. BRITISH MEDICAI, JOURNAL, February 11th, 1905, p. 285 . Etiologie 9 Deuteronomy iii, 28 .

WE quoted recently from Nature Professor Minchin's account of the discovery of the pupa of the tsetse fly in loose crumbling soil around the roots of bananas in a plantation on the shore of Albert Edward Lake, and added his statement that the fly was found on the deserted island of Kimmi, where there were no banana plantations. In a further communication to Nature Professor Minchin states that he is informed by Lieutenant A. C. H. Gray, R.A.M.C. that there are deserted banana plantations on Kimmi. Should it turn out that the pupa only frequents the soil around bananas, the difficulty of attacking the pest will be great, since the plantations cannot be destroyed, bananas being the principal food of the natives. Professor Minchin suggests that something might be done if the natives were encouraged to keep fowls in the plantations; the birds would probably find the pupae and devour them readily. He suggests that an experiment in this direction should be made on the island of Kimmi.
SEVENTY-FOURTH ANNUAL MEETING OF THB

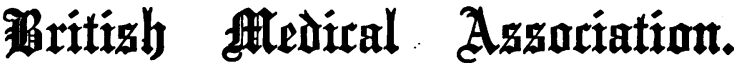

Held at Toronto, August 21st, 22nd, 23rd, 24th, and 25th, 1906.

PROCEEDINGS OF SECTIONS.

SECTION OF SURGERY.

Sir Hector Clare Cameron, M.D., President.

\section{A DISCUSSION ON ACUTE SEPTIC} PERITONITIS.

\section{OPENING PAPER.}

By C. J. BOND, F.R.C.S.,

Honorary Surgeon, Leicester Infirmary.

BEFORE entering on the technical part of the subject before us, allow me to express my deep sense of the honour you have done me in asking me to open the discussion on the Treatment of Septic Peritonitis at this important meeting of the British Medical Association in the city of Toronto.

My interpretation of the duties of the important post assigned to me is as follows:-

That I should endeavour to lay before you as fully and fairly as the time will allow the surgical position of this important matter as it stands to-day, together with any suggestions or impressions which may have occurred to me as the result of my own personal experience; to compare as far as I am able the practice of English surgeons with those of Canada and America, and to suggest for your consideration any lines of inquiry which call for further investigation.

Now, at the very threshold of my remarks I wish to pay my tribute to the very valuable and untiring labours of Canadian and American workers in this important field. In fact, much of our knowledge of the bacteriology of peritonitis, and much help in the differentiation and recognition of the different forms of the disease, we owe to our transatlantic colleagues, among whom may I be allowed to mention only the names of Cushing, Crile, Welch, Flexner, Cannon and Murphy, Fowler, Conte, Knott, Keen, and Kelly; while other well-known workers are present with us to-day.

In England the laborious and important work of Dudgeon and Sargent and Hewitson, and on the Continent that of Tarval and others, have placed the bacteriology of the disease on a more scientific basis.

Nor must we forget the important inquiries into the possibility of immunization carried out by Dr. Miyake, of Japan, under the direction of that lamented surgeon, von Mikulicz, or the valuable impetus which was given to the treatment of peritonitis by Lawson Tait, not only surgically, but especially through his strenuous advocacy of aperients as the proper substitute for opium in the medical treatment of the disease.

Those of us who can unfortunately look back some twenty-five years will thankfully acknowledge with me that though when confronted to-day with a case of acute generalized septic peritonitis (to which condition of things I understand our remarks are limited) our position is still one of grave anxiety, yet it is not as hopeless or as powerless as it was a quarter of a century ago.

We have learned in that time, and especially in the latter portion of it, to do certain things which we then feared to do, and to leave undone certain things now which we then blindly carried out. For instance, we now open the abdomen at the earliest possible moment, in order, if possible, to overtake the disease; and we now carefully avoid the evisceration and the wiping away of the protecting fibrinous lymph deposit-both such potent lethal measures in our earlier attempts at surgical interference.

Before, however, we can usefully discuss the surgical treatment of this very fatal disease, we must have some picture in our minds of its etiology and pathology, and 1 